\title{
Research on Hubei Urbanization Construction with Eco-regional Characteristics*
}

\author{
Jianian Liang \\ School of Art and Design \\ Wuhan University of Science and Technology \\ Wuhan, China 430065 \\ Liyuan Li \\ School of Art and Design \\ Wuhan University of Science and Technology \\ Wuhan, China 430065
}

\author{
Yi Zhou \\ School of Art and Design \\ Wuhan University of Science and Technology \\ Wuhan, China 430065 \\ Xiao Liang \\ Wuhan Landscape Architectural Design Institute \\ Wuhan, China 430014
}

\begin{abstract}
Vigorously advancing urbanization construction in Hubei is an important strategy to promote the rise of central China. Hubei Province's urbanization rate is higher than the average level of the whole country. In the process of construction, below staged-related problems are encountered: the integrity of the overall natural ecological security pattern needs to be strengthened urgently, the human landscape resources are not fully explored and utilized, and urbanization doesn't have prominent spatial and regional characteristics. It is proposed to strengthen the eco-civilization characteristics of Hubei Province's urbanization by a series of major construction projects, such as waterfront public space, loop ecological corridor and campus ecological education base, etc.
\end{abstract}

Keywords-new-type urbanization; eco-civilization; Hubei characteristics

\section{INTRODUCTION}

The study on Hubei Province's urbanization construction with regional ecological characteristics is essentially a study on how to shape eco-regional characteristics in the process of urbanization construction. As early as 1953, F. Gibbard published "Town Design", which explores the characteristics and artistry of cities \& towns with a lot of cases and from five aspects: aesthetic theory of history and vision, general plan, urban centre, residential area and industry. The famous Italian architect Aldo Rossiputs forward rationalistic typology and analogical city method to analyze urban characteristics in his "Urban Architecture"; and American scholar Harry describes the main components of urban identity in "Maintaining the Spirit of Place - the Protective Process of Urban Characteristics". We have to say, that it give us a lot of inspiration from western countries' study on ecological characteristics of urbanization construction from natural geography to economic society and then to people's

*Fund Project: The phased achievement of the project "Research on Embodying Eco-Regional Characteristics in the Urbanization Construction of Hubei Province" by Hubei Social Sciences Association-Hubei Think Tank. Project number: HBSXK201630; psychological feelings.

The research on urban characteristics in China was mainly carried out after 1980 s. It can be summarized into two parts: theoretical research and applied research. The theoretical research mainly focuses on the definition, origin, cognitive methods and elements, etc of urban characteristics. For example, Mr. Ma Wuding's "On Urban Characteristics" defines urban characteristics from aesthetic point of view, and analyses urban characteristics from the aspects of beauty of life and art. Zhang Qinnan puts forward the concept of generalized resource in his book "Characteristic Victory Discussion of Architectural Theory", and explores formation of Chinese architecture, urbanization characteristics and its theoretical development features; Zhang Jigang's "Analysis and Maintenance of Urban Characteristics" applies philosophical analysis method and system theory viewpoint; he has made a profound analysis of urban characteristics' elements from the integrity and interior of city. Yu Baichun's "Prerequisites and Evaluation of Urban Characteristic Resources" sets up an evaluation method for characteristic resources based on the presupposition of urban characteristic resources. More researches focus on the characteristics of a region or a city. This kind of targeted researches can be operated in certain degree, such as Chen Wensheng's "Conception of Zhanjiang City's Characteristics" and Wang Yuan and Zhang Tianxin's "Theoretical Research on Characteristics of Tropical Coastal Cities", etc.

As the natural environment, human history, social form and economic life of each urban city are different; the elements which constitute urban characteristics are different. Positioning study on urban characteristics based on the specific elements, and studies on real cases occurred at different city, different urbanization planning phase, and urbanization design phase, exactly are studies on urbancharacterized application filed. The shaping of urban ecoregional characteristics has become the main trend in the study of urban characteristics. 
How to "vigorously promote green urbanization" based on local conditions? It's really a great achievement and will also benefit future people to follow the basic principles of new-type urbanization construction of "green \& low-carbon eco-civilization," and "cultural inheritance, highlight characteristics", to fully excavate natural and humanistic resources, and to promote the urbanization of Hubei province with the characteristic of ecological civilization construction process.

\section{ECO-REgIONAL CHARACTERISTIC PROBLEMS IN HuBEI PROVINCE's URBANIZATION PROCESS}

\section{A. The Integrity of Natural Landscape Pattern Are Neglected During Construction Process}

Natural landscape pattern generally refers to the original geographical elements of the city itself, which covers the natural composing elements such as mountains, lakes, rivers, wetlands, etc., and the relationship among mountains, rivers, cities and forests, such as the relative location between natural mountains and rivers, the size, direction, composing and arrangement order of natural mountain \& river system, the combination factors of mountain, river, city and forest, etc., also includes the transformation and supplement of natural landscape by human beings. The integrity of natural landscape pattern of Hubei's urbanization construction is affected, mainly in the following aspects:

1) Destruction to natural water ecology cannot be fully stopped: The spread of expressways and the expansion of urban scale have destroyed the original natural landscape matrix; the matrix of waterscape pattern is fragmented. Take Wuhan as an example: intercepting rivers and filling lakes to expand city have seriously damaged the integrity of water pattern. In recent years, strong and heavy rainfall in Wuhan always seriously floods the city and paralyses the traffic, which caused a lot of complaint.

The rapid urbanization process has also brought many negative impacts on the waterscape's ecological infrastructure, especially destruction along rivers and lakes. Many natural revetments are occupied by artificial buildings. Lot of rough and even non-skid artificial revetments with safety risks have appeared. Field research found that some inlet and outlet of river revetments are roughly built, with hydropower instruments exposed on surface and weeds growing over. Some enterprises do not pay enough attention to the construction of environmental protection facilities; and sewage is discharged into rivers without strict treatment. In some areas, urban residents discharge domestic sewage at will.

2) Natural mountain ecology are destroyed: The natural appearance of mountain is destroyed by quarrying, mining and road construction; vegetation is peeled off the mountain; rocks are exposed everywhere. Mountains are "black and blue all over", and some are flattened or become water pits; the contour of mountains is occupied by buildings, whose density, height and shape are quite inconsistent with the overall environment. Mountains' natural contours are severely damaged. The public resources are divided by the surrounding units, some of which become the backyard of different units, and are not allowed to visit by local residents; the mountain lost its function of urban public space. With the growth of population in mountain area, people's demand for natural resources increases gradually, and the excessive transformation of natural mountain leads to the imbalance of natural ecology; rocky desertification appeared in mountain area. In Wuhan, 58 mountains in the main urban area were excavated at will, and $18.19 \%$ mountains are seriously damaged. The slope of Fenghuang Mountain in Wuchang is flattened, the whole mountaintop of Yuanbaoshan Mountain is leveled, and some mountains have disappeared completely, with only name left.

3) Construction of Urban green space system lags behind: First problem is structure of garden green space system. The corridor construction of urban green space is insufficient, and the network system between green spaces needs to be optimized; the overall quality of mountainous forest vegetation in urban area is degraded, and the ecological effect of landscape is not up to the standard. The level of urban green space facade landscape is not clear, and planned plants in green space system are getting more and more. Phenomena like "seeking farther instead of nearer", "big trees moving to urban cities" and so on still exist in planting.

Second problem is green coverage. As city planning is not predictable, newly built green spaces are destroyed because of new construction. For example, because of the subway construction in Wuhan, the decades-old platanus orientalis trees on Wuluo Rd disappeared overnight. Green belts along many streets such as Xiongchu Street are pushed down again; human totally controls the age of trees. Small cities like Tianmen, Xiantao, Qianjiang, etc fall behind in green belt construction. Urban green coverage and green space rate are not balanced, resulting in big gap between urban green space landscape and people's expectations.

\section{B. Urban Human Ecological Landscape Don't Have Prominent Characteristics}

Human ecological landscape resources are sum of material and spiritual civilization achievements created independently since the founding of human society. They can not only effectively inherit the historical context, but also can fully display the unique charm of city.

1) Urban spatial environment lacks unique characteristics: In urbanization construction of Hubei Province, human cultural resources are not fully utilized, and local regional characteristics are neglected. The government only emphasizes construction and economy development, but ignores the inheritance of urban history context; as a result, historic buildings and traditional cultural blocks are wantonly destroyed. Protection planning, policy establishment, management and operation of relevant historical and cultural cities, towns, villages and historic cultural heritage are far from perfect. 
The protection for traditional buildings is rigid and not flexible. The true owners of some historic villages, traditional streets and well-known buildings have no right to repair these heritages, while the government has failed to maintain them in time. Many are collapsed and destroyed under the beaten of weather. Due to people's concept and economic conditions, there is no fundamental breakthrough in the ecological architecture design and popularization. In some cities, the scale of architectural space and planning is out of control, and the landscape color is sufficient; the Jingchu cultural and artistic characteristics tend to be diluted.

2) Ecological heritage of vernacular landscape is ignored: "Vernacular Landscape Ecological Heritage" refers to landscape elements, land patterns and spatial linkage which have great significance to the construction of urban-rural landscape characteristics and people's spiritual needs. In the process of Hubei province's urbanization, Vernacular Landscape heritage doesn't get enough attention, protection and restoration. Taking Zhujialou Village in Hongan County as an example, the village's family tree has record of "Jufang Garden", but we cannot find any clue of "Jufang Garden" this village's new countryside \& tourism landscape planning. The elements and cultural spirit of "Jufang Garden" are not reflected in the new landscape design, so its cultural value as the spiritual sustenance of villagers is lost. Ancestral halls, archways and ancient buildings scattered in countryside are also gradually destroyed. For example, Yan's Temple, an ancient building in Jiufanggou Village, Dawu County, has been listed as a cultural relic protection unit at the county level, but it has collapsed with only the external walls and gate buildings left; apparently the protection is far from enough.

\section{SHAPING ECO-REGIONAL CHARACTERISTICS OF URBAN SYSTEM THROUGH KEY PROJECTS}

We should enhance green infrastructure construction system in urban area, maintain the overall continuity of landscape pattern, highlight elements of "mountain", "river", and "green" in urban planning and design, and give this large province enough exhibition space. We should maintain the relationship between natural landscape and cities, and let people truly see mountains and water, so as to achieve the opening and sharing of natural landscape. We should build the network system of vernacular landscape with Hubei characteristics, carry out the survey of local heritage landscape, compile "Network Protection plan for Hubei Province's vernacular heritage landscape", so as to form a continuous and integral landscape pattern network, which can fully play the unique role of rural revitalization. We should generally promote the "double-repair" work of urban ecology, focus on the restoration of mountains, rivers, and lakes, promote the construction of "sponge cities" and Green villages, and strengthen the transformation and upgrade of townscape, vegetation landscape, architectural color \& style, urban advertising media, urban outline and urban nightscape brightening, etc.

\section{A. Ecological Construction Project of Urban Waterfront Public Space}

1) Establishing green life at Yangtze River Axis (Hubei section): We should strengthen the ecological environment work in the river \& lake regions, enhance the supervision and comprehensive management of the ecological environment along the Yangtze and Hanjiang rivers in Hubei region, respect the natural law and the river evolution law, promote the development of green cycle and low carbon, and build the ecological corridor safety pattern with sufficient regional ecological flow, effective soil and water conservation and diverse biological species; we should scientifically guide the development of cities and towns along the River. Relying on Wuhan, Yichang, Ezhou, Huangshi and other large and medium-sized cities, establish and protect groups of "green wedges" ecological bond and maintain relationship between cities and towns. Depending on the natural eco-geographical environment, properly determine the urban performance and spatial form, and build a new intensive, efficient, green and low-carbon urbanization system; we should setup the ecological Golden Corridor along the Yangtze River coastline, protect coastline's original scenery, and strengthen the construction of landscape signs along the Yangtze River, such as Dragon King's Temple, Guanyin Pavilion, Dongpo Red Cliff, Three-Kingdoms' Red Cliff, and Xisaishan Mt, etc and also the space construction of beach landscape along Yangtze River, Hanjiang River etc; so as to create the world's longest golden "landscape corridor".

2) Intensifying urban waterfront space construction with ecological characteristics : We should combine artificial slope protection and natural ecological revetment for coastal landscape, to maintain the accessibility of rivers, lakes and harbor water, so that ecological revetment can fully adjust water level to avoid flood and drought and can also promote harmony and stability of natural ecosystem. We should maintain the continuous opening space of cities with rivers and lakes, expand ditches connecting rivers \& lakes, so as to ensure the diversity and integrity of water space; we should timely remove the "garbage" buildings along the waterfront, and construct a new space order of waterfront landscape based on mountains, water and people; we should highlight the outline of mountains and forest, to guarantee a transparent and orderly landscape. We should enhance the lighting at hydrophilic space, waterfront pedestrian sites and coastline to form waterfront glorious zones, so as to build a new order of waterfront landscape space with mountains as basis, water as lifeline and people as root.

3) Paying attention to the shaping of urban skyline: Urban Skyline often displays a city's overall image in a panoramic way, which determines people's overall understanding and evaluation of the city. If build a high-rise building in city's overall environment, its height should coordinate with the geographical contours, its appearance complete with other elements of the city, and its volume 
keep certain scale relationship adjacent buildings. With Yangtze River and Hanjiang River flowing through many cities in Hubei Province, many urban areas are rich with waterscape; we can build a graceful city skyline with rich layers based on the broad view of rivers and lakes, which can become the landmark and symbolic landscape of the city. We can learn skyline construction experience from Singapore, Shanghai and Hongkong, etc to activate the charm of urban space.

\section{B. Construction Project of Ecological Civilization Education Demonstration Base in Campus}

Campus landscape refers to a variety of natural and human landscape complexes with ornamental, cultural and ecological significance. There are many colleges and universities in Hubei, and we can find "ecological garden campus" everywhere, which plays a decisive role in a city's overall ecological outlook.

1) Optimizing the planning and design of campus and highlighting the ecological characteristics of natural landscape : We should skillfully take topographic fluctuation as landscape skeleton, and constantly change the observation angle, to give people a sense of change in motion. Wuhan University is built on Luojia Hill. Its picturesque natural scenery is praised as the "paradise" of Wuhan's three towns, and it has become "one of the most beautiful universities in the world". We can also fully take advantages of Meijiashan, Yujiashan, Guizishan, Lianhuashan and also water system like Sanjiao Lake, Huangjiahu Lake, Nanhu Lake etc, to create "mountainriver" campus landscape ecology.

2) Perfecting campus green space system: Osmanthus, cherry blossom, rape flower, peach blossom, lotus, sycamore and other trees and flowers have made Wuhan University, Huazhong Normal University, and Huazhong Agricultural University, etc become the city's characteristic scenery. We should continue to make use of ornamental flowers and trees to highlight the ecological characteristics of university's natural landscape, to improve the security of the waterfront zone and the ornamental value of plant environment, to strengthen the characteristics of the humanistic landscape, and to expand the ecological education and the environmental effects of intellectuals.

\section{3) Shaping humanistic landscape of campus} architecture, etc: Artificial landscape, such as campus architecture and color, bears the history and culture of the university, and it focuses on the function of educating people and the construction of space environment. We should highlight cultural characteristics of the Han and Jingchu schools' architectures, to reflect the inclusive and pluralistic unity of universities' cultural spirit. Let the campus architecture and other humanistic landscapes highlight the advantages of university context or discipline advantage, and create campus's humanistic personality. We should make use of different campus' local characteristic change to realize general ecological Harmony.

4) Intensifying eco-environment consciousness cultivation: We should strengthen the construction of pedestrian space and encourage walking or bicycling; encourage people to form eco-energy-saving habits such as garbage classification, turning off lights when leaving, reducing noise, paperless documents, cleaning-plate action, etc, to minimize the use of disposable chopsticks, paper cups, to lower the living cost, so as to stop plundering and occupying nature; gradually ecological and cultural awareness and behavior can be found everywhere. We should take advantage of the resources like campus museums, libraries and science \& technology museums, to mobilize environmental volunteers, experts and scholars to lead popularization work of green ecological science and demonstration work of ecological construction technology ,so as to let colleges and universities fully act as ecological education foundation.

\section{Ecological Corridor Construction Project of Bridge Landscape and Town Ring Line}

1) Build a province of bridge landscape design: Frederick Gottemoeller, an American bridge landscape scientist, believes that the bridge landscape is the art of designing bridges, including the overall layout, shape, line, color expression and material texture of the bridge landscape. Wuhan Yangtze River Bridge, as the first roadrailway dual-purpose bridge on roaring Yangtze River, has made Wuhan become the focus of bridge landscape in the whole country. It is for this reason that the collaboration between Hubei province's bridge design departments and landscape design, material development and engineering construction units should be strengthened so as to highlight Hubei's characteristics in bridge design and construction. The bridge landscape names should not only reflect the natural environment characteristics of the bridge landscape region, but also highlight the cultural connotation of Jingchu culture and the artistic attributes of writing and producing.

2) Constructing ecological appreciation corridor for urban ring and inter-city high-speed link: "One super city \& two vice super cites" and "two city circles \& two ecological belts" are the actual urban space pattern in Hubei; the city-ring green belt can be carried out based on this pattern. Strengthen the overall planning of urban ring lines and urban links in provincial areas, and strictly control the general environmental layout and ecological construction along roadside within the range of 50 meters, 200 meters and 2000 meters. The road construction should respect the natural form of mountains, waters, plains and hills etc., illegal buildings and visual pollution sources should be demolished; view nodes can be setup for proper rest \& sightseeing, which can not only keep smooth visual space, but also improve scenery's ornamental recognition; We also 
should optimizes the ecological corridor bridge, life passage, and guarantee the quantity and quality of the safe corridors for reptiles. In slope-preserving, skillfully take advantage of rocks, flowing water and plants to create beautiful landscapes. We should respect the original habitats along both sides of the green belt, which should meet the requirements of sunshine heating and sunshade in different seasons; we should pay attention to the application of local plants and planting materials, select trees and plants with strong adaptability, strong growth force, barren-tolerance, diseases and insect resistance, and weak lateral branches and strong vertical branches.

\section{CONCLUSION}

Hubei's urbanization construction is still in rapid development period. Urbanization "is a strong powerful engine to keep sustained economic development, an important focus to accelerate industrial transformation and upgrading, a strong support to promote the harmonious development of the regions in Hubei, and an inevitable requirement to stimulate all-round social progress". Only by adhering to ecological civilization construction road and strengthening the connotation of Jing-Chu human and natural ecological characteristics, can we achieve the goal of urbanization \& ecology in Hubei Province, and further to promote the sustainable development of the Yangtze River Economic Zone and to produce the demonstration effect of the construction of beautiful China.

\section{REFERENCES}

[1] Chen Caixia, Intercultural Awareness Cultivation in College English Teaching [J]. Journal of Bingtuan Education Institute, 2009 (2). (in Chinese)

[2] Department of Higher Education, Ministry of Education. The College English Curriculum Requirements [M]. Beijing: Foreign Language and Teaching Press, 2007. (in Chinese)

[3] Jiang Junli, Chen Jiang, Intercultural Awareness Cultivation in English Teaching[J]. Journal of Hunan Radio and Television University, 2008 (3). (in Chinese)

[4] Yang Ming'e, Importance of Intercultural Awareness Cultivation in English Teaching[J]. Guangxi Journal of Light Industry, 2009(7). (in Chinese)

[5] Zhao Li, Intercultural Awareness Cultivation and Penetration in English Teaching [J]. Heilongjiang Higher Education Research, 2007 (6). (in Chinese) 